\title{
ENTREPRENEURSHIP ACTIVITIES AND ENTREPRENEURSHIP COMPETENCIES OF ESTONIAN UNIVERSITY GRADUATES FROM BIO- ECONOMY FIELDS
}

\begin{abstract}
Anne PÕDER, Institute of Economics and Social Sciences, Estonian University of Life-Sciences, Kreutzwaldi St. 1a Tartu, 51014 Estonia, anne.poder@emu.ee

Constant and rapid global economic and social developments and environmental processes create considerable new challenges, but also new opportunities for bio-economy. Entrepreneurs have a crucial role harnessing the new opportunities and addressing the challenges through innovation. The aim of the present paper is to study the entrepreneurship activities and entrepreneurial competencies of Estonian university graduates in the fields connected with bio-economy. The paper studies the data from a survey of three Estonian universities carried out in 2016 in the program "Systemic Development of Entrepreneurship education throughout all educational levels". The analysis focuses on the share of entrepreneurs, assessments of the entrepreneurship competencies among the alumni, who graduated university in the fields of agriculture, forestry, fisheries; life-sciences, and veterinary medicine, and on their comparison with alumni of the other curricula. Chi-square test, ANOVA are used the compare the entrepreneurship activities, competencies of alumni of different curricula. The results show that the graduates' field of study had significant impact on their entrepreneurship activities after the graduation, and on the attainment of entrepreneurship competencies. A quarter of the agriculture, forestry and fisheries, and a fifth of veterinary alumni were entrepreneurs, although a significantly smaller share of them in comparison with graduates of other fields had received entrepreneurship education during their studies. The share of entrepreneurs was lowest among all the fields of study in case of life-sciences alumni. The study demonstrates the need to integrate entrepreneurship education into the agricultural and lifesciences education and to address the attainment of key competencies in university's curricula.
\end{abstract}

Keywords: entrepreneurship competencies, entrepreneurship education, alumni, university, bio-economy

\section{INTRODUCTION}

Entrepreneurship not only creates jobs and economic growth, but also has central role in driving innovation and renewal of economic fabric (Fayolle, 2007). Following the economic crises, entrepreneurship development in EU has been lagging behind in comparison with several international competitors, thus it has been acknowledged on the EU level that more entrepreneurial culture, more support of entrepreneurship and entrepreneurship education are required to create economic growth, new jobs and increase competitiveness (EC, 2013). Competence refers to a combination of knowledge, skills and social competences that are needed for certain activities (Delamare, Winterton, 2005). Entrepreneurship as one of the necessary competencies for a knowledge-based society does not narrowly only refer to carrying out a business activity, but to an ability to implement one's ideas in variety of fields and the skills and knowledge needed to achieve one's objectives (Recommendation of ..., 2006).

Many studies (Peterman, Kennedy, 2003; Kuratko, 2005; GEM, 2006; Van Praag, Versloot, 2007) emphasize that the provision of entrepreneurial learning opportunities has a favorable impact on entrepreneurship, economic growth and innovation. In the last decades, the attention to entrepreneurship education has considerably increased in the universities (Kuratko, 2006). The role of entrepreneurship education is to support the development of entrepreneurial mindsets in students by helping them the develop their skills sets, knowledge and behavioral patterns necessary for entrepreneurial behavior (Moberg et al. 2014). Higher education institutions have a central role in developing the entrepreneurship education. Entrepreneurship education helps students to develop their entrepreneurial skills, the ability to detect opportunities and to set up new enterprises (Kirby et al., 2011). Entrepreneurship education has impact on the propensity and intentions of graduates to become entrepreneurs (Pittaway, Cope, 2007). While the importance of entrepreneurship education has been acknowledged, its outcomes have received less attention (Moberg et al. 2012). In Estonia some previous research on entrepreneurship education (Kolbre et al. 2006, Raudsaar, Kaseorg 2016) mostly focused on whether different universities provided entrepreneurship courses, but its effect on the later entrepreneurship activities of alumni has received no attention.

Copyright (C) 2017 The Authors. Published by Aleksandras Stulginskis University. This is an open-access article distributed under the terms of the Creative Commons Attribution License (CC-BY 4.0), which permits unrestricted use, distribution, and reproduction in any medium, provided the original author and source are credited. 
Entrepreneurship skills, knowledge and attitudes are highly relevant for societies that are exposed to considerable economic, social and environment challenges. Bio-economy as the economy based on the use of renewable biological resources is seen as one of the main solutions in responding to the resource scarcity, environmental pressures, climate change and in transforming the present economic, social and environmental practices. The bio-economy growth strategy of EU emphasizes the need to invest into knowledge, innovation and skills to achieve a change in the way biological resources are used, processed, consumed etc. (EC, 2012). Universities are one of the main stakeholders as they both conduct the research on bio-economy, but also teach the students, whose future activities will determine the practices of how the resources will be used. But in order for them to make a change, they need to develop necessary entrepreneurship skills and knowledge in order to recognize the new opportunities from bio-economy and to actually seize them.

The aim of the present analysis is to study the entrepreneurship activities and entrepreneurship competencies of Estonia university alumni, who graduated from university in the fields connected with bio-economy - agriculture, forestry, fisheries; life-sciences; veterinary medicine. Their entrepreneurship activities and ability to innovate will have considerable impact on whether the potential of bio-economy in Estonia will be realized. The analysis focuses on the share of entrepreneurs among the alumni; and on whether the graduates of bio-economy fields were provided entrepreneurship education during their university studies; and whether the studies helped them to develop different entrepreneurship competencies.

\section{RESEARCH METHODOLOGY}

The importance of entrepreneurship education and its role in the development of students' entrepreneurship competencies has been also acknowledged by Estonian Ministry and Education and Research (MER). In 2016, MER implemented a program "Systemic Development of Entrepreneurship education throughout all educational levels", cofinanced by the European Social Fund, with the aim to facilitate entrepreneurship education in Estonia across all levels of education (HTM, 2016). In 2016, an alumni survey was carried out in the program by three higher education institutions: Estonian University of Life-Sciences (EMÜ), Estonian Academy of Arts (EKA) and Estonian Entrepreneurship University of Applied Sciences (EEK). The aim of the survey was to study the entrepreneurial activities of the alumni, collect feedback on the entrepreneurship education they had received during their studies, assessments on the development of different competencies and on the content of the curricula etc. The data collected with the survey was used the assess the current entrepreneurship education, its shortcomings and need for improvement. The survey provided input for the entrepreneurship teaching materials and modules that were developed in the entrepreneurship education program as well as information on the share of entrepreneurs among the graduates and the specifics of the entrepreneurial activities.

The data collection was carried out by an internet- based questionnaire survey in the summer and fall of 2016 . The present analysis focuses on the alumni, who graduated from the three institutions in the last 10 years - 1051 respondents. $62.6 \%$ of the respondents were women and $28.4 \%$ were men. The average age of the respondents was 31,7 .

The present paper concentrates on the share of entrepreneurs, whether the graduates received entrepreneurship education, and on the assessments of development of entrepreneurship competencies during their studies. In the survey, entrepreneurs were defined as individuals who were self-employed or owners and managers of a commercial enterprise or a non-profit organization. Entrepreneurship education was studied with a question whether the respondents received any entrepreneurship courses during their studies. The alumni were also asked to assess how did their studies help them to develop different competencies. The respondents assessed a list of 22 competencies in a Likert-type of scale of five (5- definitely yes ... 1 - definitely no).

The study included respondents from all curricula of the three institutions and from bachelor, master and doctoral levels. In the analysis, the respondents were grouped on the basis of their field of study. In the present analysis, main focus is on three groups of fields of studies connected with bio-economy: agriculture, forestry and fisheries; life-sciences; veterinary science. The other curricula (business and administration; arts; architecture and construction; engineering, manufacturing and technology) have been grouped into one group for the analysis (other). In the following analysis chisquare test is used to study if the field of study impacted the entrepreneurship education and share of entrepreneurs among the alumni. ANOVA is used to study if the development of different entrepreneurship competencies depended on the students' field of studies.

\section{RESULTS}

The share of entrepreneurs among the alumni that graduated from the three institutions in the other field of studies (business and administration; arts; architecture and construction; engineering, manufacturing and technology) in the last ten years was $27,4 \%$ (Fig. 1). The chi-square test showed that the association between the field of studies and whether the respondent was entrepreneur at present was statistically significant $\left[\chi^{2}(3)=16,9 ; p<.001\right]$. The share of the entrepreneurs was lowest among the life-sciences graduates with only $11,3 \%$ of them currently owning and managing their own enterprise or non-profit organization. The share of entrepreneurs among the veterinary sciences and agriculture, forestry and fisheries graduates was higher than in life-sciences, but still lower than in case of graduates of other fields. 


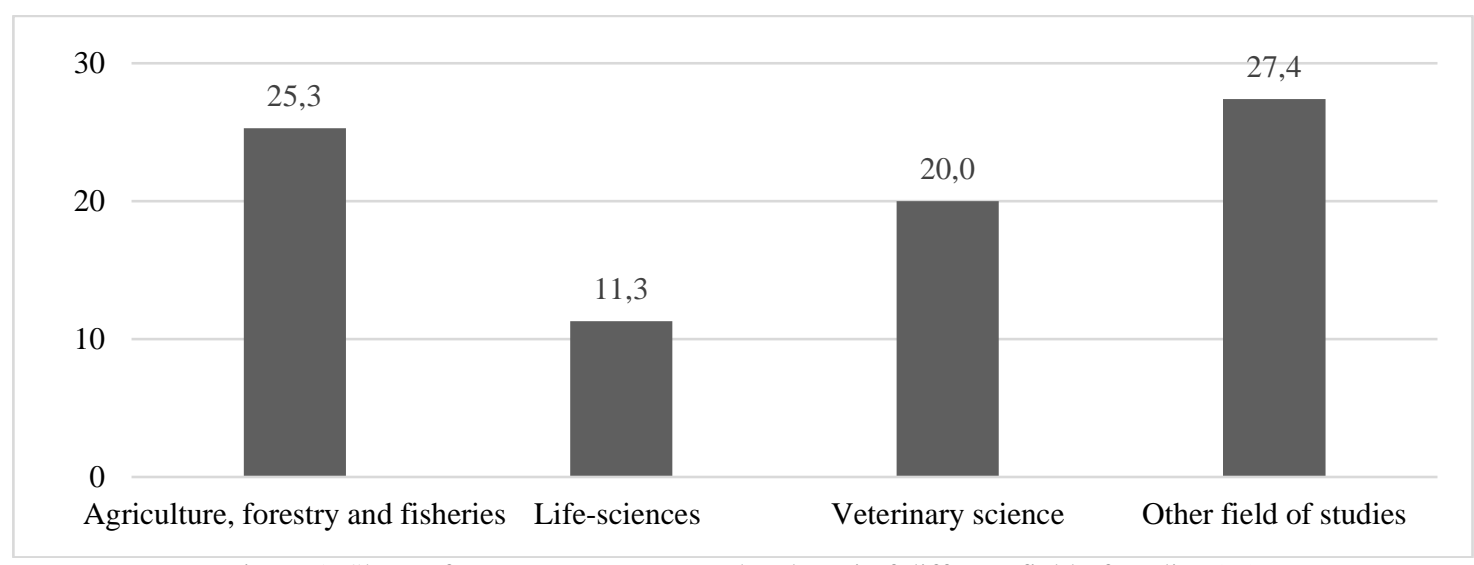

Figure 1. Share of entrepreneurs among the alumni of different field of studies (\%)

The alumni study also collected information on when did the alumni become entrepreneurs. The average age for becoming an entrepreneur was 29,3. However, the field of study had significant impact [in ANOVA F $(3,220=4,2 ; p<.01$ ] On average, the graduates of life-sciences become entrepreneurs at the age of 32,2. In case of the agriculture, forestry and fisheries alumni the average age for starting with entrepreneurial activities was significantly lower - 26,3. In case of veterinary alumni and the alumni from other fields, the average age when they started with entrepreneurship was respectively 29,3 and 29,8 .

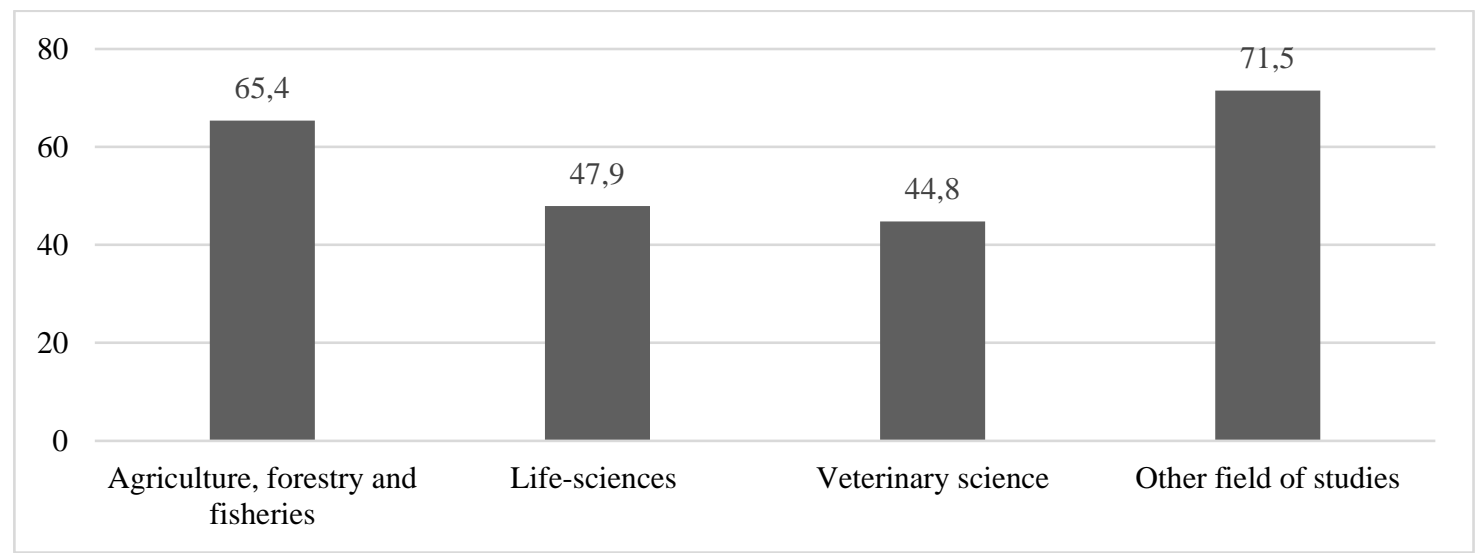

Figure 2. Share of alumni, who had received entrepreneurship courses during their university studies (\%)

In comparison with other fields of study, the three groups studied (agriculture, forestry and fisheries; life-sciences; veterinary medicine) have also received significantly less entrepreneurship education $\left[\chi^{2}(3)=30,1 ; p<.000\right]$. Less than half of veterinary sciences and life-sciences alumni had participated in entrepreneurship courses during their studies (Fig. 2). The entrepreneurship education was more integrated into the curricula of agriculture, forestry and fisheries students as considerably higher share of them received entrepreneurship courses, but it was still significantly less in comparison with alumni from the other four fields.

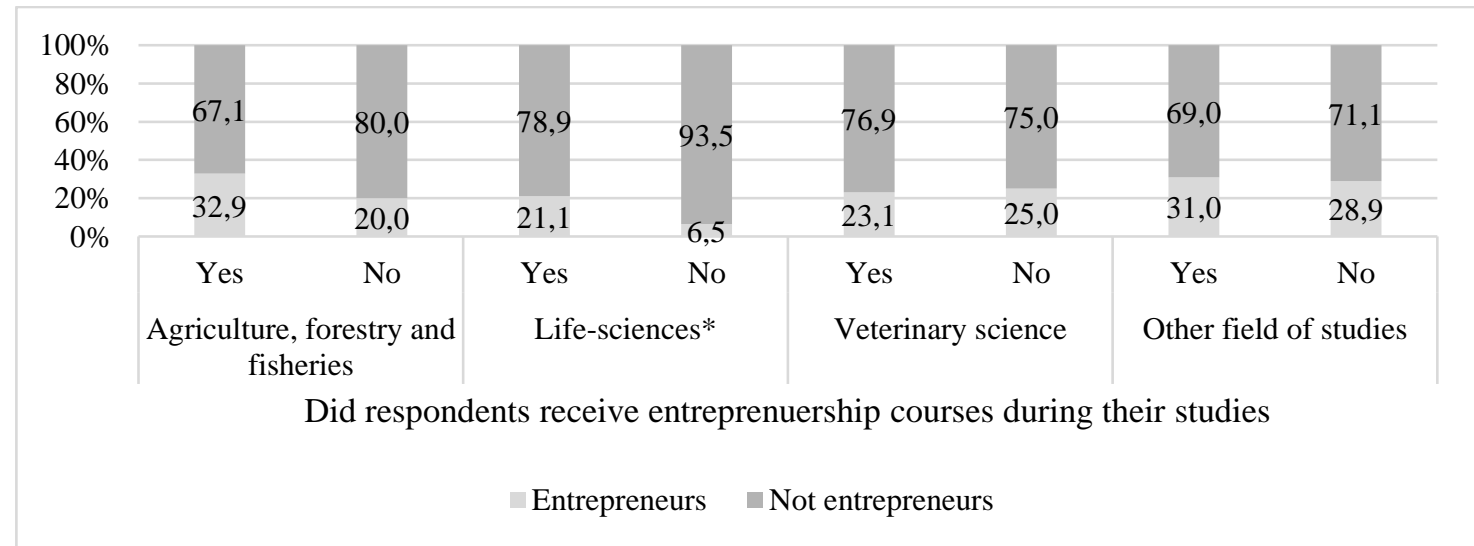

Figure 3. Alumni entrepreneurs and whether they received entrepreneurship courses during their university studies $p<.05 ; * * p<0.01 ; * * * p<.001$

In case of agriculture, forestry and fisheries; life-sciences and other field of studies, the share of entrepreneurs was somewhat higher in case of alumni, who has received entrepreneurship courses during their studies (Fig. 3). For veterinary 
graduates, the share of entrepreneurs was higher among those who had not participated in any entrepreneurship courses. The chi-square tests, however, revealed that the effect of participation in entrepreneurship courses on whether the students became an entrepreneur was not significant with one exception. In case of life-sciences alumni, the participation in entrepreneurship courses significantly increased likelihood that the students become entrepreneurs after their university studies $\left[\chi^{2}(1)=5,4 ; p<.05\right]$. The share of entrepreneurs among those who had received entrepreneurship education was $21,1 \%$ in comparison with just $6,5 \%$ of those who had not received any entrepreneurship courses.

One of the goals of the study was to collect the information for the analysis on what kind of competencies students attained during their studies. The list of 22 competencies was compiled on the basis of literate review, development of framework for entrepreneurship education, analysis of the content of present curricula and the feedback from the lecturers teaching entrepreneurship in the three institutions. Figure 4 presents the mean scores given by the respondents and whether the difference in mean scores was statistically significant in the ANOVA. In overall, the highest scores were given to the development of competencies connected with constant self-improvement, oral and written expression, independence, communication skills etc. Financial knowledge, leadership skills and knowledge of entrepreneurship received the lowest scores.

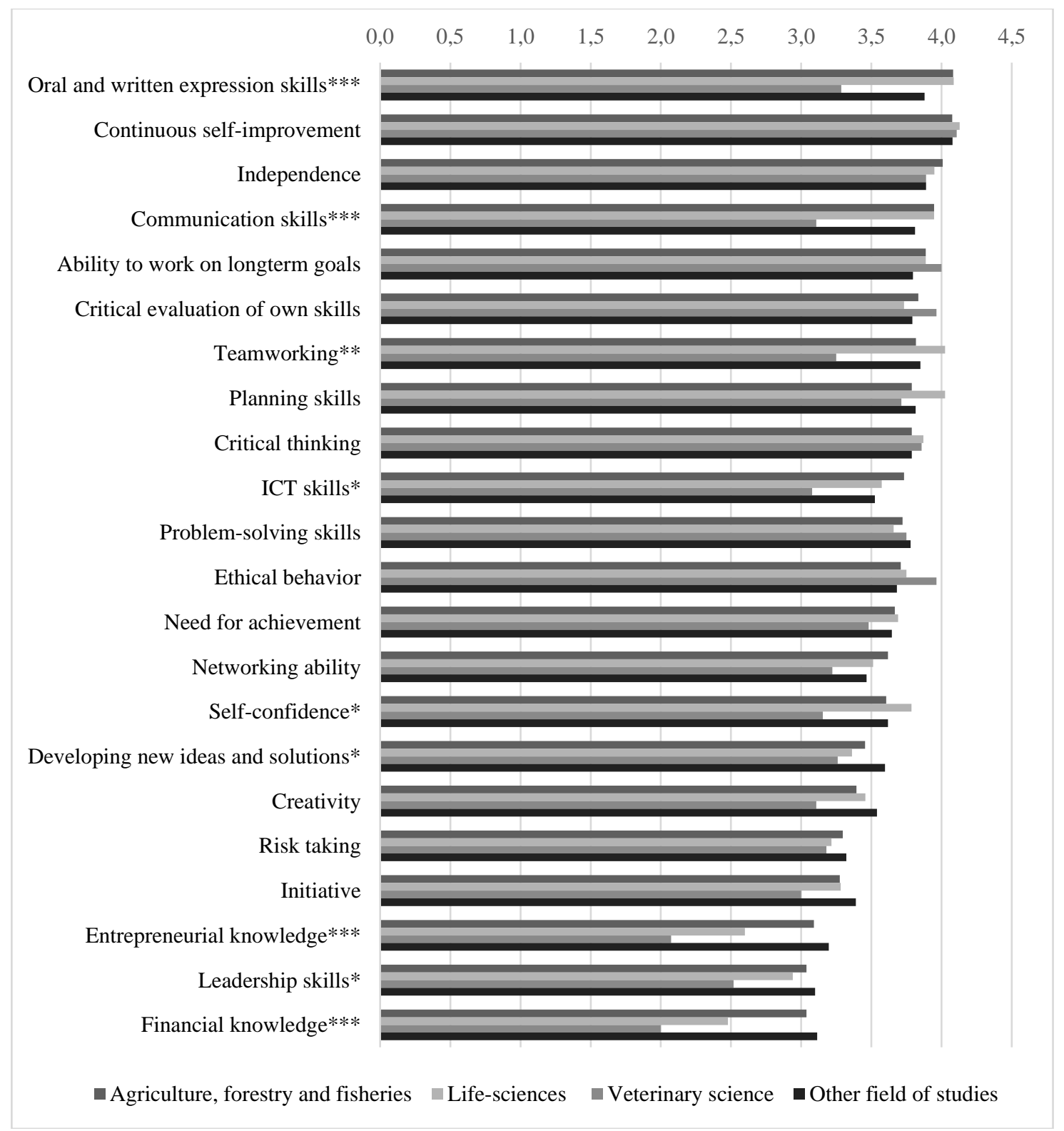

Figure 4. Mean scores on the attainment of entrepreneurship competencies during the studies $* p<.05 ; * * p<0.01 ; * * * p<.001$

The results of ANOVA showed that differences in the mean assessments were statistically significant in case of 9 competencies out of 22 (Fig. 4). The difference in assessments were highest in case of financial knowledge and entrepreneurial knowledge. This could be expected as the students in the veterinary science and life-sciences has received considerably less entrepreneurship education and thus gave also lower scores on the attainment of those competencies. However, it also stands out that the graduates for veterinary science alumni gave lower scores to the oral and written expression skills, communication skills, leadership skills, ICT skills and on the ability to develop new solutions in 
comparison with the alumni of other groups. In comparison with other, the respondents who had graduated from the lifesciences curricula, gave higher scores to the development of skills for team-working and self-confidence.

\section{CONCLUSION}

The results of the alumni entrepreneurship study have considerable implications for the further development of entrepreneurship education in Estonian universities and in the field of bio-economy. In the last decade, the provision of entrepreneurship education has been highly inconsistent in Estonian higher education institutions, and dependent on the field of study. This reflects also in the entrepreneurial activities of the alumni graduating in the fields that are connected with bioeconomy as the share of entrepreneurs among the alumni of agriculture forestry and fisheries; veterinary medicine and lifesciences is significantly lower. The present Estonian entrepreneurship policy sees ICT; health technologies and efficient use of resources as the priority areas with highest growth potential (MEAC,2013). Agriculture forestry and fisheries; veterinary medicine and life-sciences are part of bio-economy directly related to the health technologies as well as bio-resources and so the lack of entrepreneurship and innovation in those fields will be a considerable problem.

The study indicated that the entrepreneurship education should be more integrated to the agricultural and lifesciences education in the Estonian universities. This is especially the case with life-sciences that were characterized by very low level of entrepreneurship and in comparison, with other fields, their graduates become entrepreneurs considerably later after the graduation. This can be addressed by integrating more entrepreneurship education into their curricula as this had significant effect in encouraging those graduates in becoming an entrepreneur.

The age of alumni, when they become entrepreneurs, provides significant information. In the development of entrepreneurship education is should be taken into consideration that most of the university graduates become entrepreneurs not right after the graduation, but after some period of time during which they obtain professional knowledge and experience in their specific field and build up their network while working as employees. So, the aim of the entrepreneurship education should not be to turn the university students into entrepreneurs right away, but to provide them with knowledge, skills and attitudes they can build on later, when they feel ready to become entrepreneurs.

Important aspect is to address the development of key competencies throughout the university studies. The lower scores for the attainment of competencies by the alumni of veterinary medicine and life-science can be explained by the fact that they had received less entrepreneurship education; however, the list of entrepreneurship competencies in the questionnaire included the skills and knowledge that are transversal competencies not narrowly connected with entrepreneurship, but necessary to success in any field. Ability to express yourself, communication and teamworking skills etc. are critical both for succeeding in labor market as well as in developing one's own enterprise. Without the development of those skills, students will not succeed in whatever career path they will take after graduating from the university.

\section{ACKNOWLEDGEMENT}

The alumni entrepreneurship survey was financed by the program "Systematic Development of Entrepreneurship Education on All Levels of Education in Estonia", implemented by the Estonian Ministry of Education and Research and co-funded by European Social Fund.

\section{REFERENCES}

1. Delamare, F., Winterton, J. 2005. What is Competence? Human Resource Development International, Vol. 8, Iss. 1, pp. $27-46$.

2. EC. European Commission. 2012. Innovating for Sustainable Growth: A Bioeconomy for Europe. Brussels: European Commission. http://ec.europa.eu/research/bioeconomy/pdf/official-strategy_en.pdf (Accessed on 02/08/2017)

3. EC. European Commission. 2013. Entrepreneurship 2020 Action Plan COM (2012) 795 Final. Brussels. http://eurlex.europa.eu/legal-content/EN/TXT/?uri=CELEX:52012DC0795 (Accessed on 30/01/2017)

4. Fayolle A. 2007. Entrepreneurship and New Value Creation: the Dynamics of the Entrepreneurial Process. Cambridge University Press, Cambridge. https://doi.org/10.1017/CBO9780511488689

5. GEM. 2006. Global Entrepreneurship Monitor Report. Babson College, Kauffman Centre for Entrepreneurship, Babson, MA and London School of Economics, London.

6. HTM. Haridus - ja Teadusministeerium. [Ministry of Education and Research] 2016. Toetuse andmise tingimused tegevuse "Ettevõtlikkuse ja ettevõtlusõppe süsteemne arendamine kõigil haridustasemetel" elluviimiseks. [Conditions for implementing "Systematic Development of Entrepreneurship Education on All Levels of Education in Estonia"] https://www.hm.ee/sites/default/files/eeta_lisa1_kinnitatud.pdf (Accessed on 02/08/2017)

7. Raudsaar, M., Kaseorg, M. 2016. Entrepreneurship education in higher education institutions: Estonian case. New Trends and Issues Proceedings on Humanities and Social Sciences, Vol. 1, Iss. 5, pp. 219-226.

8. Kirby, D. A., Guerrero, M., \& Urbano, D. 2011. Making universities more entrepreneurial: development of a model. Canadian Journal of Administrative Sciences. Revue Canadienne des Sciences de l'Administration, Vol. 28, Iss.3, pp. $302-316$.

9. Kolbre, E., Piliste, T., Venesaar, U. 2006. Entrepreneurship Education and Entrepreneurial Initiative in Estonia. Entrepreneurship in Estonia: Policies, Practicies, Education and Research. Tartu: Tartu University Press, pp. 248-269.

10. Kuratko, D. 2005. The emergence of entrepreneurship education: Development, trends, and challenges. Entrepreneurship, Theory \& Practice, Vol. 29, Iss. 5, pp. 577-598. https://doi.org/10.1111/j.1540-6520.2005.00099.x 
11. MEAC. Ministry of Economic Affairs and Communication. 2013. Estonian Entrepreneurship Growth Strategy 2014-2020. http://kasvustrateegia.mkm.ee/pdf/Estonian\%20Entrepreneurship\%20Growth\%20Strategy\%202014-2020.pdf (Accessed on 28/10/2017)

12. Moberg, K., Vestergaard, L., Fayolle, A., Redford, D., Cooney, T., Singer, S., Sailer, K., Filip, D. 2014. How to assess and evaluate the influence of entrepreneurship education. A report of the ASTEE project with a user guide to the tools. Odense: The Danish Foundation for Entrepreneurship - Young Enterprise. http://archive.ja-ye.org/Download/jaye/ASTEE_REPORT.pdf (Accessed 06/08/2017)

13. Moberg, K., Vintergaard, C., Vestergaard, L. 2012. Evaluating content dimensions in entrepreneurship education. I Kotzeva, M., Schmiemann, M. (eds). Entrepreneurship determinants: culture and capabilities. Eurostat Statistical books. Luxembourg: Publications Office of the European Union. pp. 89-98.

14. Peterman, N.E., Kennedy, J. 2003. Enterprise education: Influencing students" perceptions of entrepreneurship. Entrepreneurship Theory and Practice. Winter, pp. 129-144. https://doi.org/10.1046/j.1540-6520.2003.00035.x

15. Pittaway, L. \& Cope, J. 2007. Entrepreneurship Education: A Systematic Review of the Evidence. International Small Business Journal: Researching Entrepreneurship, Vol. 25, pp. 479-510. https://doi.org/10.1177/0266242607080656

16. Recommendation of the European Parliament and of the Council of 18 December 2006 on key competences for lifelong learning. 2006. Official Journal of the European Union L 394, 30.12.2006. http://data.europa.eu/eli/reco/2006/962/oj (Accessed on 28/10/2017)

17. Van Praag, C.M., Versloot, P. 2007. What is the value of entrepreneurship? A review of recent research. Small Business Economics, Vol. 29, Iss. 4, pp. 351-382. https://doi.org/10.1007/s11187-007-9074-X 